\title{
Intrinsic Dynamics in Neuronal Networks. II. Experiment
}

\author{
P. E. LATHAM ${ }^{1,2,3}$ B. J. RICHMOND ${ }^{2}$ S. NIRENBERG,${ }^{1}$ AND P. G. NELSON ${ }^{3}$ \\ ${ }^{1}$ Department of Neurobiology, University of California at Los Angeles, Los Angeles, California 90095; ${ }^{2}$ Laboratory of \\ Neuropsychology, National Institute of Mental Health, National Institutes of Health; and ${ }^{3}$ Laboratory of Developmental \\ Neurobiology, National Institute of Child Health and Human Development, National Institutes of Health, Bethesda, \\ Maryland 20892
}

Latham, P. E., B. J. Richmond, S. Nirenberg, and P. G. Nelson. Intrinsic dynamics in neuronal networks. II. Experiment. J. Neurophysiol. 83: 828-835, 2000. Neurons in many regions of the mammalian CNS remain active in the absence of stimuli. This activity falls into two main patterns: steady firing at low rates and rhythmic bursting. How these firing patterns are maintained in the presence of powerful recurrent excitation, and how networks switch between them, is not well understood. In the previous paper, we addressed these issues theoretically; in this paper we address them experimentally. We found in both studies that a key parameter in controlling firing patterns is the fraction of endogenously active cells. The theoretical analysis indicated that steady firing rates are possible only when the fraction of endogenously active cells is above some threshold, that there is a transition to bursting when it falls below that threshold, and that networks becomes silent when the fraction drops to zero. Experimentally, we found that all steadily firing cultures contain endogenously active cells, and that reducing the fraction of such cells in steadily firing cultures causes a transition to bursting. The latter finding implies indirectly that the elimination of endogenously active cells would cause a permanent drop to zero firing rate. The experiments described here thus corroborate the theoretical analysis.

\section{N T R O D U C T I O N}

Many areas of the mammalian CNS exhibit neuronal activity in the absence of stimuli. Two patterns of activity that are commonly observed are steady firing at low rates and rhythmic bursting. How do dynamic interactions between excitatory and inhibitory neurons produce these firing patterns? Specifically, how do networks remain stable in the face of powerful recurrent excitation, and how do they switch between steady firing and bursting? In the previous paper (Latham et al. 2000) we investigated these questions theoretically. We found that firing patterns are controlled largely by one parameter, the fraction of endogenously active cells; i.e., the fraction of cells that fire without input. When no endogenously active cells are present, networks are either silent or fire at a high rate; as the number of endogenously active cells increases, there is a transition to bursting; and with a further increase, there is a second transition to steady firing at a low rate. The main assumptions in our theoretical analysis were conventional: excitatory input to a neuron increases its firing rate, inhibitory input decreases it, and neurons exhibit spike-frequency adaptation.

In this paper we explore experimentally the link between endogenous activity and intrinsic firing patterns. To achieve

The costs of publication of this article were defrayed in part by the payment of page charges. The article must therefore be hereby marked "advertisement" in accordance with 18 U.S.C. Section 1734 solely to indicate this fact. the control necessary to effectively test the theoretical predictions, we used cultured mouse spinal cord neurons. Such networks are easily accessible, are amenable to pharmacological intervention, and are consistent with critical model assumptions, including the existence of spike-frequency adaptation (Kernell 1965, 1972; Tseng and Prince 1993) and the expression of both excitatory and inhibitory neurons (Nelson et al. 1981). In addition, cultured networks retain many of the properties of networks in vivo, such as rich connectivity and complex patterns of spontaneous activity (Basarsky et al. 1994; Gross et al. 1993; Kamioka et al. 1996).

We performed two sets of experiments. In the first, we investigated the relationship between low firing rates and the existence of endogenously active cells. As predicted, we found that every culture that fired at low rates contained endogenously active cells. Moreover, the mean fraction was relatively high, $\sim 30 \%$ on average. In the second, we investigated the relationship between firing patterns and the fraction of endogenously active cells. Again as predicted, we found that a reduction in the fraction of endogenously active cells led to bursting.

These experimental findings are in agreement with the theoretical results presented in the previous paper. This agreement suggests that we have developed a realistic model for the intrinsic dynamics of large neuronal networks, and supports the idea that the fraction of endogenously active cells plays a key role in shaping firing patterns.

\section{METHODS}

\section{Cell culture}

Neurons from the ventral horn of the spinal cord were dissociated from 13.5-day-old fetal mice, and cortical glial and support cells were dissociated from the cortex of newborn mice (Nelson et al. 1989, 1990). The ventral horn neurons were plated on a confluent layer of nonneuronal cortical cells plated $1 \mathrm{wk}$ previously. The growth media was Eagle's minimum essential media (MEM, formula no. 82-0234DJ with Earle's salts, $3.7 \mathrm{~g} / \mathrm{l}$ of sodium bicarbonate, $6.0 \mathrm{~g} / \mathrm{l}$ of D-glucose, and without L-glutamine; $\mathrm{pH}$ 7.3-7.5; 320-330 mOsmol; GIBCO Laboratories, Grand Island, NY), supplemented with 5\% horse serum (Summit Biotechnology, Fort Collins, CO), L-glutamine $(2 \mathrm{mM})$ and the following additional factors: $200 \mu \mathrm{g} / \mathrm{ml}$ transferrin, $200 \mathrm{nM} \mathrm{pu}-$ trescine, $60 \mathrm{nM}$ sodium selenite, $20 \mathrm{ng} / \mathrm{ml}$ triiodothyronin, $10 \mu \mathrm{g} / \mathrm{ml}$ insulin, $40 \mathrm{nM}$ progesterone, and $40 \mathrm{ng} / \mathrm{ml}$ corticosterone (Fitzgerald 1989; Romijn et al. 1982; Sheng et al. 1993). Cultures were grown at $35^{\circ} \mathrm{C}$ in a humidified $10 \% \mathrm{CO}_{2}$ atmosphere. Mitosis of nonneuronal cells was inhibited after 2 days by the addition of $13 \mu \mathrm{g} / \mathrm{ml} 5$-fluoro2 '-deoxyuridine. Cultures were maintained with half-media changes. 


\section{Patch recording}

Recordings were made in three different media as follows. 1) Growth media, as describe above. 2) $\mathrm{NaPO}_{4}$ buffered media (MEM, catalog no. 11430 with Earle's salts and without L-glutamine, $\mathrm{pH}$ 7.3-7.5, 320-330 mOsmol, GIBCO) supplemented with L-glutamine $(2 \mathrm{mM})$ and the same additional factors used in the growth media (Fitzgerald 1989; Romijn et al. 1982; Sheng et al. 1993). The $\mathrm{NaPO}_{4^{-}}$ buffered media differed from the growth media primarily by the replacement of sodium bicarbonate by $\mathrm{NaPO}_{4}$ and the elimination of horse serum. 3) Reduced media, which consisted of (in $\mathrm{mM}$ ) 145 $\mathrm{NaCl}, 4.5 \mathrm{KCl}, 10 \mathrm{HEPES}, 10$ glucose, $0.8 \mathrm{MgCl}_{2}$, and $1.8 \mathrm{CaCl}_{2}$, along with $2 \%$ BSA (20 g/l); pH 7.3; 325 mOsmol adjusted with sucrose $(\sim 5 \mathrm{~g} / \mathrm{l})$.

The first two media are referred to as "fortified" media to distinguish them from the third, reduced media, which contains only essential salts and no other factors. This distinction is made because the neurons behaved differently in the third media than they did in the first two, and we exploited this difference to test one of the theoretical predictions made in the previous paper.

Whole cell recordings were made using patch electrodes $(2-10$ $\mathrm{M} \Omega$ ) filled with a solution containing (in $\mathrm{mM}$ ) $145 \mathrm{KAc}, 5 \mathrm{NaCl}, 2$ $\mathrm{MgCl}_{2}, 5 \mathrm{HEPES}, 1$ EGTA, and $0.1 \mathrm{CaCl}_{2}$. Membrane potential was measured under current-clamp mode. Extracellular patch recordings (Hamill et al. 1981) were also made using patch electrodes (2-10 M $\Omega$ ) filled with a solution containing (in $\mathrm{mM}$ ) $145 \mathrm{NaCl}, 4.5 \mathrm{Kcl}, 1.8$ $\mathrm{CaCl}_{2}, 0.8 \mathrm{MgCl}_{2}, 1.0 \mathrm{HEPES}$, and 10 glucose. Action potentials were recorded in voltage-clamp mode. All recordings were at room temperature $\left(21-23^{\circ} \mathrm{C}\right)$.

Recordings were made with an Axopatch-1B amplifier (Axon Instruments). Signals were filtered at $500 \mathrm{~Hz}$, digitized at $20 \mathrm{kHz}$, and stored on a Power Macintosh 7600/132 using a 16-bit analog-todigital converter (ITC-16; Instruteck, Elmont, NY) under control of the program Synapse (Synergy Research, Silver Spring, MD). Spike extraction was done off-line by thresholding the voltage. Because there was variation in the spike amplitude relative to the noise, the threshold was set individually for each cell.

\section{Measuring the mean firing rate of cultured networks}

For each culture, the activity of five or more neurons was monitored using extracellular patch recordings. The mean firing rate was then computed. If two or more of the examined neurons were silent, the culture was discarded.

\section{Treatment with blockers}

NEUROTRANSMITTER RECEPTOR ANTAGONISTS. Ten percent of the media from a culture was removed and combined with antagonists. The media was then returned to the culture, bringing the antagonist concentrations to the values shown in Table 1.

TETANUS TOXIN. Cultures were first washed with $\mathrm{NaPO}_{4}$ buffered media to remove the horse serum. This is necessary because horse serum contains antibodies to tetanus toxin. The toxin was then applied to the cultures in $\mathrm{NaPO}_{4}$-buffered media at a concentration of 1 $\mu \mathrm{g} / \mathrm{ml}$. Because tetanus toxin acts slowly, the application was done $>6 \mathrm{~h}$ before physiological analysis of the cultures to ensure a complete block of transmitter release (Bergey et al. 1987). The tetanus toxin $\left(2 \times 10^{7}\right.$ mouse lethal doses per mg protein) was generously provided by Dr. William Habig, CBER, FDA, Bethesda, MD.

\section{Burst detection and measurement}

Following Dekhuijzen and Bagust (1996) we used the difference between successive interspike intervals as our assay for bursting. That difference, denoted $\delta t_{n} \equiv\left(t_{n+1}-t_{n}\right)-\left(t_{n}-t_{n-1}\right)$ where $t_{n}$ is the time of the $n$th spike, has a unimodal distribution in nonbursting cultures and a trimodal distribution in bursting ones (Dekhuijzen and Bagust 1996). The two side peaks in the trimodal distribution correspond to transitions between long interspike intervals (the time between bursts) and short interspike intervals (the intervals within a burst). To establish the existence of side peaks, we computed the kurtosis, denoted $K_{\delta}$, of the distribution of the $\delta t_{n}: K_{\delta} \equiv\langle(\delta t-$ $\left.\mu)^{4}\right\rangle / \sigma^{4}$, where angle brackets denote an average over the $\delta t_{n}, \mu \equiv\langle\delta t\rangle$ is the mean of $\delta t$, and $\sigma^{2} \equiv\left\langle(\delta t-\mu)^{2}\right\rangle$ is its variance. Trimodal distributions have large kurtosis compared with those with a single peak, so, on average, bursting cultures have larger kurtosis than nonbursting ones. Differences in kurtosis between bursting and nonbursting cultures were evaluated using the Student's $t$-test.

To determine the burst period, we convolved the spike trains with a Gaussian of width $0.5 \mathrm{~s}$ and computed the mean time between the peaks of the convolved waveform. Empirically, we found that this method worked well for cells in reduced media when the kurtosis was $>6.5$. When the kurtosis was below that value, which typically happened when the bursts were irregular or the number of spikes per burst was small, spurious peaks were introduced that gave inaccurate estimates of the true interburst interval. Of the 27 cells in reduced media, 18 had kurtosis greater than 6.5.

To determine the mean firing rate during bursts, we convolved the spike trains with a Gaussian of width $0.5 \mathrm{~s}$, thresholded the resulting waveform at one-fifth of its peak, and averaged the portion of the waveform that was above the threshold. This method was relatively insensitive to our choice of thresholds: cutting the threshold in half produced, on average, a 15\% drop in firing rate; doubling it produced, on average, a $30 \%$ increase in firing rate. The mean rate during a burst is far less sensitive to irregular bursting and spurious peaks than the interburst interval, so all cells were included when calculating the mean rate.

\section{RES ULTS}

\section{Cultures that fire steadily at low rates contain endogenously active cells}

Cultured networks that fire steadily at low rates were examined for endogenously active cells by blocking synaptic transmission in the network and recording neuronal activity. If cells show activity when all synaptic transmission is blocked, they are considered endogenously active. Transmission was blocked two ways: 1) by binding neurotransmitter receptors with antagonists and 2) by preventing neurotransmitter release using tetanus toxin.

CULTURES WERE ACTIVE IN THE PRESENCE OF NEUROTRANSMITTER RECEPTOR BLOCKERS. Nineteen cultures were examined to assess mean firing rates as described in METHODS. Ten showed steady firing at low rates, with rates ranging from

TABLE 1. Neurotransmitter receptor antagonists

\begin{tabular}{llc}
\hline \hline \multicolumn{1}{c}{ Antagonist } & \multicolumn{1}{c}{ Receptor Blocked } & $\begin{array}{c}\text { Concentration } \\
(\mu \mathrm{M})\end{array}$ \\
\hline $\begin{array}{l}\text { 2-Amino-5-phosphonopentanoic } \\
\text { acid (AP5) }\end{array}$ & $\begin{array}{l}N \text {-Methyl-D-aspartate } \\
\text { (NMDA) }\end{array}$ & 100 \\
$\begin{array}{l}\text { 6-Cyano-7-nitroquinoxaline-2,3- } \\
\text { dione (CNQX) }\end{array}$ & $\begin{array}{l}\alpha \text {-Amino-3-hydroxy-5- } \\
\text { methyl-4 }\end{array}$ & 10 \\
& $\begin{array}{l}\text { isoxazoleproprionic } \\
\text { acid (AMPA) }\end{array}$ & \\
$\begin{array}{l}\text { Mecamylamine } \\
\text { Atropine } \\
\text { Bicuculline }\end{array}$ & $\begin{array}{l}\text { Muscarinic acetylcholine } \\
\gamma \text {-Aminobutyric acid-A } \\
\text { (GABA })\end{array}$ & 100 \\
Strychnine & Glycine & 20 \\
\hline
\end{tabular}




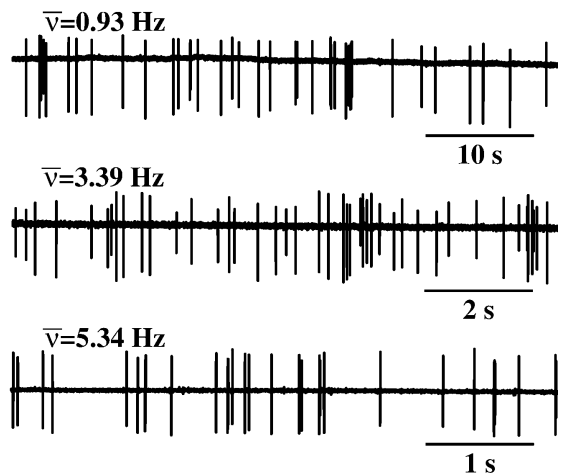

FIG. 1. Extracellular patch recordings showing examples of steadily firing neurons. For each cell, the mean firing rate averaged $>300 \mathrm{~s}, \bar{\nu}$, is shown above the trace, and the scale bar is shown below the trace.

$0.72 \pm 0.18 \mathrm{~Hz}$ (mean $\pm \mathrm{SE}, n=5$ cells) to $4.10 \pm 1.34 \mathrm{~Hz}$ ( $n=6$ cells); the remaining cultures were silent and not used. Representative examples of the firing patterns of neurons in culture are shown in Fig. 1.

Cultures containing steadily firing neurons were treated with neurotransmitter receptor antagonists to block synaptic transmission (Table 1). The antagonists were chosen to block all the major fast transmitter receptors in the spinal cord, which are the receptors for glutamate, acetylcholine, glycine, and GABA $_{\mathrm{A}}$ (Betz 1991; Malcangio and Bowery 1996; Mayer and Westbrook 1987; Wang et al. 1990), and one slow excitatory receptor, the metabotropic acetylcholine receptor, which is also expressed in the spinal cord (Wang et al. 1990). To verify that synaptic transmission was disrupted, cells were examined for the presence of postsynaptic potentials (PSPs) using whole cell patch recordings. The criterion for an effective block was the absence of PSPs for at least $1 \mathrm{~min}$, as determined by visual inspection of the time course of the membrane voltage. In no cases were fast (several ms rise time) PSPs observed ( $n=1-2$ cells per dish, 13 cells total). The absence of fast PSPs is shown in Fig. 2 for a cell that was not active in antagonists and in Fig. 3 for one that was.

Once it was established that synaptic transmission was blocked, as indicated by the absence of fast PSPs, neuronal activity was examined. To minimize perturbation to the examined cells, extracellular patch recordings were used. All cultures that fired steadily under control conditions contained neurons that were active in the presence of antagonists (Fig. 4). The mean fraction of active cells was $30 \pm 5 \%(n=10$ experiments; 86/285 active cells). Seven of the cultures were returned to control media, and all regained their original pre-
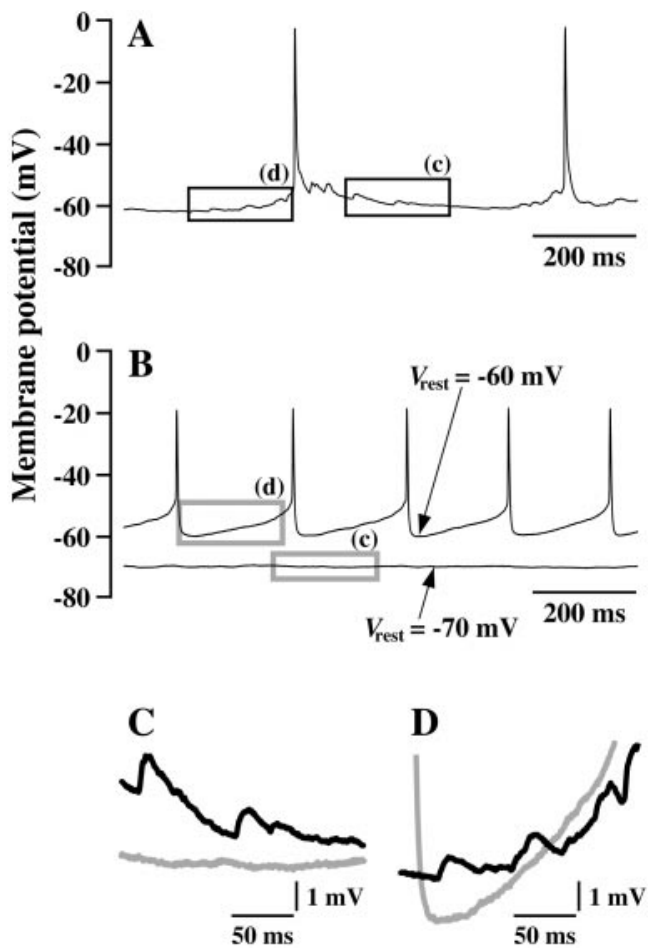

FIG. 3. Postsynaptic potentials do not drive cells in antagonist-treated cultures. A: whole cell recording in the absence of antagonists. PSPs are clearly visible. $B$ : whole cell recording of a different neuron in the presence of antagonists. Top trace corresponds to zero injected current and a resting membrane potential near $-60 \mathrm{mV}$. In the bottom trace the cell is hyperpolarized to $-70 \mathrm{mV}$, which eliminates activity. PSPs are not visible in either trace. $C$ : expanded-scale view of the membrane potential in a region with no spikes-the boxes marked (c) in $A$ and $B$. $D$ : expanded-scale view of the membrane potential in a region immediately preceding a spike-the boxes marked (d) in $A$ and $B$. In both $C$ and $D$ the gray trace is the voltage in the presence of antagonists, the black trace is the voltage in their absence. Even at the expanded scale, no PSPs are visible in the cell treated with antagonists.

blocked firing patterns and low rates, indicating that the neurons remained healthy throughout the experiment: five of seven showed rates not significantly different after being returned to control media $(P>0.1$, Student's $t$-test), whereas two of seven showed slightly higher rates.

An additional test of the effectiveness of the blockers was provided by examining the distribution of interspike intervals before and after antagonists were added to the cultures. With synaptic transmission blocked, cells should fire much more regularly, because input from other cells provides a timevarying signal that increases variation in firing times. To char-

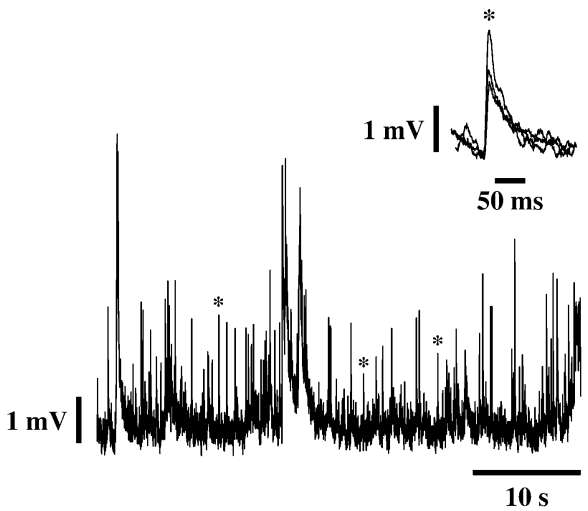

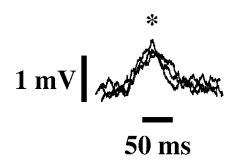

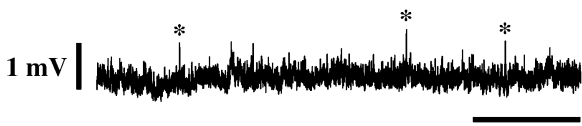

FIG. 2. Whole cell recordings from the same neuron before (bottom left trace) and after (bottom right trace) the addition of neurotransmitter receptor antagonists. Voltage transients marked with asterisks are shown on an expanded scale. Voltage transients in the presence of antagonists (top trace, right side) lack the sharp rise and slow decay characteristic of postsynaptic potentials (PSPs; top trace, left side), and are presumably noise. The absence of fast PSPs in the right trace indicates that the antagonists used provided an effective block of neurotransmission. 


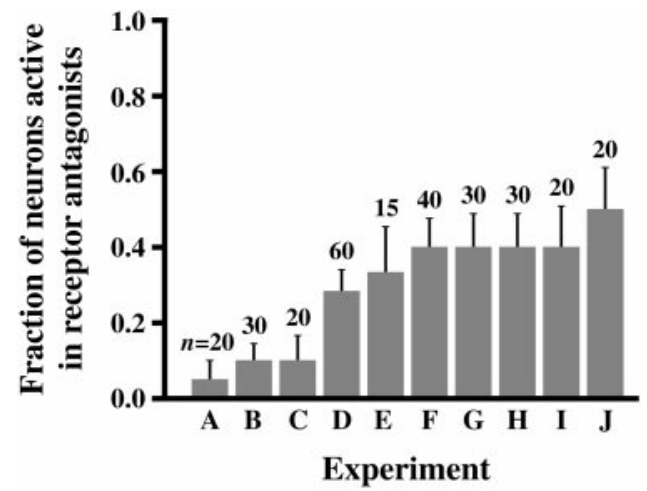

FIG. 4. Fraction of cells active in the presence of neurotransmitter receptor antagonists for 10 experiments, labeled $A-J$. The number above each bar is the number of cells examined for activity in each experiment. Error bars were constructed assuming that the number of active cells follows a binomial distribution: for experiments in which $m$ out of $n$ cells were active in the presence of antagonists, the height of the error bar is $\sqrt{(m / n)(1-m / n) / n}$. All cells were firing steadily before antagonists were added, with rates ranging from 0.2 to $8.5 \mathrm{~Hz}(2.3 \pm 2.2 \mathrm{~Hz}$, mean $\pm \mathrm{SD}, n=56)$.

acterize the degree of regularity, we used the coefficient of variation $(\mathrm{CV})$, the standard deviation of the interspike interval distribution divided by the mean. We found that cells fired significantly more regularly in the presence of receptor antagonists $\left(P<10^{-4}\right.$, Student's $t$-test): the mean CV was $0.47 \pm$ $0.05(n=77$ cells $)$ in the presence of antagonists and $1.18 \pm$ $0.06(n=56$ cells) in their absence (Fig. 5).

CULTURES WERE ACTIVE IN THE PRESENCE OF TETANUS TOXIN. While the absence of fast PSPs and the high degree of regularity in the firing provide strong indication that the neurotransmitter receptor antagonists block synaptic transmission, we cannot rule out the possibility that some transmission remains. In particular, it is possible that there were slow PSPs that we did not detect, such as those produced by metabotropic glutamate receptors or neuromodulators. For this reason, an alternative and independent method was used to block synaptic transmission, tetanus toxin, which blocks neurotransmitter release (Bergey et al. 1983). Tetanus toxin also circumvents the potential problem that some receptor antagonists have been reported to act as weak agonists for excitatory amino acid and neuromodulator receptors (Collingridge and Lester 1989; Colquhoun and Patrick 1997).

Two sets of experiments were performed. In the first, cul-

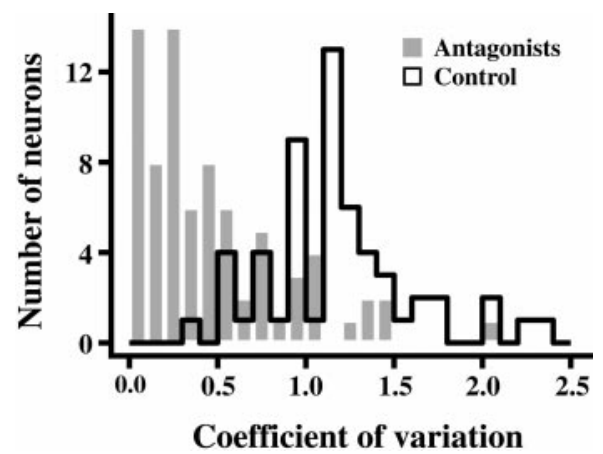

FIG. 5. Histogram of coefficient of variation (CV) for cells in the presence of neurotransmitter receptor antagonists (gray bars) and in their absence (outlined bars). The mean CV was $0.47 \pm 0.05$ (mean $\pm \mathrm{SE}, n=77$ cells) in the presence of antagonists and $1.18 \pm 0.06(n=56$ cells $)$ in their absence. These means were significantly different $\left(P<10^{-4}\right.$, Student's $t$-test $)$. tures were treated with antagonists, and the fraction of active cells was measured. The cultures were then washed and treated with tetanus toxin (see METHODS), and the fraction of active cells was measured again. Schematically, the procedure was Antagonists $\rightarrow$ Wash $\rightarrow$ Tetanus.

In the second, cultures were treated with tetanus toxin first, and the fraction of active cells was measured. Antagonists were then added and the fraction of active cells was measured again. Because the action of tetanus toxin is irreversible on the time scales of these experiments, the latter recordings were performed in the presence of both blockers of synaptic transmission. Schematically, this procedure was Tetanus $\rightarrow$ Tetanus + Antagonists.

Both sets of experiments are summarized in Fig. 6. The mean fraction of active cells in tetanus toxin was $35 \pm 8 \%$ $(n=5$ experiments; 100 cells $)$, and the mean fraction active in both tetanus toxin and antagonists was $38 \pm 3 \%(n=2$ experiments; 40 cells). These fractions were indistinguishable from the $30 \pm 5 \%$ of cells active in antagonists $(P>0.7$, ANOVA). Measured across all experiments (antagonists, tetanus toxin, and tetanus toxin plus antagonists), the mean fraction of cells active in blockers was $32 \pm 4 \%(n=17$ experiments; 136/425 active cells).

There was also a statistically significant drop in the coefficient of variation when the cells were transferred from control conditions to tetanus toxin $\left(P<10^{-4}\right.$, Student's $t$-test), and thus a significant increase in the regularity of firing. The CV was $1.12 \pm 0.09(n=26$ cells $)$ in control media and $0.30 \pm$ $0.05(n=50$ cells $)$ in media containing tetanus toxin or tetanus toxin plus antagonists.

In sum, blocking synaptic transmission with neurotransmitter receptor antagonists and tetanus toxin produced the same results: they both showed that neurons remained active even when they were not receiving synaptic input. These results indicate that networks that fire at low rates contain endogenously active cells.

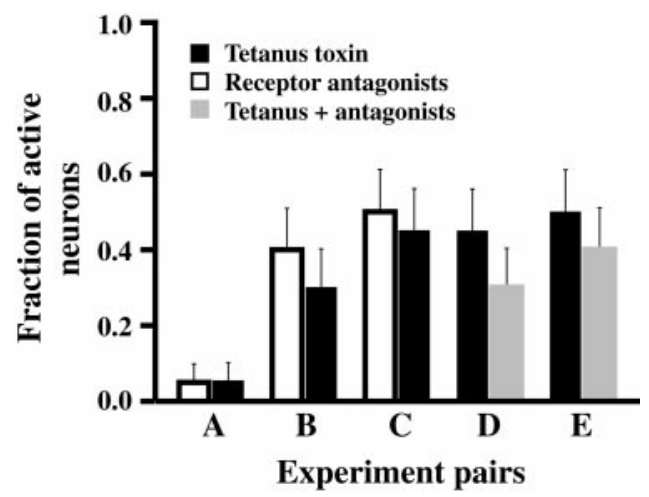

FIG. 6. Comparison of the fraction of cells active in tetanus toxin with the fraction in neurotransmitter receptor antagonists for 5 sets of experiments, labeled $A-E$. As in Fig. 4, the error bars were constructed assuming the fraction of active cells follows a binomial distribution. In each experiment, 20 cells were examined for activity. The tetanus toxin-treated cultures and the cultures treated with both tetanus toxin and antagonists yielded a fraction of endogenously active cells that was indistinguishable from experiments in antagonists alone $(P>0.7$, ANOVA). Furthermore, on a culture-by-culture basis, there was no significant difference between cultures treated with tetanus toxin and those treated with antagonists (1st 3 pairs), or between those treated with tetanus toxin and those treated with tetanus toxin + antagonists (last 2 pairs) $(P>0.5,2$-sided confidence test approximating the binomial distribution as a Gaussian). 
Reducing the fraction of endogenously active cells leads to bursting

Although low firing rates require endogenously active cells, such cells do not guarantee steady firing. As shown in the companion paper (Latham et al. 2000), the fraction of endogenously active cells must be above some threshold to ensure steady firing; below that threshold, networks bursts.

In the previous section, we showed that networks exhibiting steady, low firing rates contain, on average, $32 \%$ endogenously active cells. In this section, we examine the prediction that reducing the fraction of endogenously active cells produces bursting. To test this prediction, it was necessary to have a method for reducing the fraction of endogenously active cells. We found, serendipitously, that culture media with only essential salts and no growth factors served this purpose. We refer to this as "reduced" media, and refer to the media used in the experiments described above as "fortified" media. When cultures were placed in reduced media, the mean fraction of endogenously active cells, averaged over cultures, was $1.1 \pm 1.1 \%(n=3$ experiments; $0 / 15,0 / 27$, and $1 / 30$ active cells). The one active cell fired steadily; i.e., it was not an endogenous burster. The fraction of endogenously active cells in reduced media was significantly lower than the $32 \pm 4 \%$ seen in fortified media ( $P<0.01$; Student's $t$-test). The effect of the reduced media was reversible: when cultures were switched from reduced media back to fortified media, the fraction of endogenously active cells increased to its characteristic level of $\sim 30 \%$.

We compared the firing patterns of cultures in reduced media, which contained few endogenously active cells, with the firing patterns of cultures in fortified media, which contained many endogenously active cells. These experiments were done in the absence of blockers. In cultures with few endogenously active cells, nearly all neurons (24/27) displayed bursting patterns (periods of activity regularly interspersed with periods of silence; see Fig. $7 A$ ). The three that were not obviously bursting were firing at

A
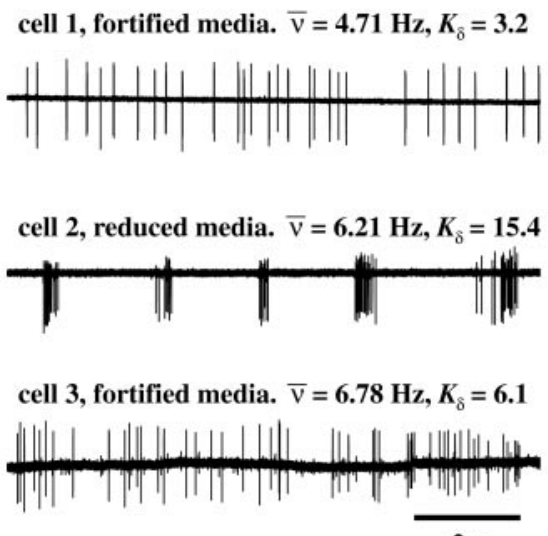

$2 \mathrm{~s}$ too low a rate to make an accurate categorization. In contrast, in cultures with many endogenously active cells, no neurons $(0 / 56)$ exhibited bursting. To quantify the difference between bursting and steadily firing cells, we computed the kurtosis of the distribution of the difference between successive interspike intervals. This quantity is sensitive to transitions between long and short interspike intervals (see METHODS). The kurtosis, denoted $K_{\delta}$, is 6 for Poisson spike trains and generally larger than 6 for bursting spike trains. In cultures with few endogenously active cells, $K_{\delta}=$ $16.3 \pm 3.0(n=27$ cells $)$. In cultures with many endogenously active cells, $K_{\delta}=5.5 \pm 0.3(n=56$ cells $)$. The difference was significant at $P<10^{-4}$ (Student's $t$-test); see also Fig. 7B. The transition to bursting as the endogenously active cells decreased is consistent with our theoretical predictions.

Was the bursting in reduced media due to network activity (i.e., did the cells burst coordinately), or was each neuron bursting independently of all the others (i.e., were the neurons endogenous bursters)? Two lines of evidence indicate that the bursting was a network phenomenon. First, of the 72 neurons examined in recording media with antagonists present, none exhibited bursting, and therefore none were endogenous bursters. Second, within a given culture, all cells examined showed similar burst periods. Variation in the burst period, as measured by the standard deviation of the burst period divided by the mean, ranged from 2 to $20 \%$. [For the 3 cultures examined, the burst periods were $8.3 \pm 0.2 \mathrm{~s}, n=4 ; 2.7 \pm 0.3 \mathrm{~s}, n=7$; and $14.7 \pm 3.1 \mathrm{~s}, n=7$ (mean $\pm \mathrm{SD}$ ). Only cells with kurtosis greater than 6.5 , for which we were able to accurately measure the interburst interval (see METHODs), were included.] This variation among neurons within a culture was comparable to the variation observed over time for individual cells: the mean magnitude of the difference between the first and last $150 \mathrm{~s}$ of the 300 -s recordings, averaged over the neurons in each culture, ranged from 4 to $18 \%$.

\section{B}

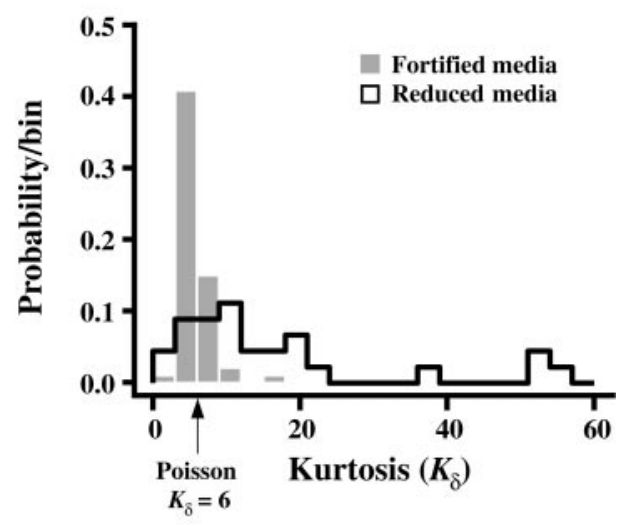

FIG. 7. Cultures exhibited bursting in reduced media, where there were few endogenously active cells $(\sim 1 \%)$, but not in fortified media, where there were many such cells $(\sim 30 \%$; see text). A: extracellular patch recordings from 3 different cells in the same culture. The culture was first placed in fortified media (cell 1, top trace), where the neurons fired steadily, then switched to reduced media (cell 2, middle trace), where the neurons burst, and, finally, switched back to fortified media (cell 3, bottom trace), where the neurons fired steadily again. $\bar{\nu}$ is the firing rate averaged over the length of the recording, $300 \mathrm{~s}$, and $K_{\delta}$ is the kurtosis, a measure of the degree of bursting. High kurtosis indicates bursting cultures; smaller values, on the order of 6 (the value achieved by Poisson spike trains) indicate steadily firing ones (see METHODS). Cell 2 was a typical burster: its mean firing rate during bursts, $10.5 \mathrm{~Hz}$, was comparable to the mean rate during bursts for the other neurons in reduced media $(8.2 \pm 4.9 \mathrm{~Hz}$, mean $\pm \mathrm{SD}, n=$ 27; see METHODS for calculation of the firing rate during bursts). $B$ : histogram of the kurtosis in fortified media (gray bars) and in reduced media (outlined bars). The mean kurtosis was $5.5 \pm 0.3$ (mean $\pm \mathrm{SE}, n=56)$ in fortified media and $16.3 \pm 3.0(n=27)$ in reduced media. These means were significantly different $\left(P<10^{-4}\right.$, Student's $t$-test). 
Finally, we can estimate the fraction of endogenously active cells at which the transition to bursting occurs. The lowest observed fraction in fortified media was 5\% (Fig. 4, Experiment A), whereas the largest observed fraction in reduced media was $3.3 \%$ (1/30, see above). This indicates that, at least under the conditions used here, the transition to bursting is likely to occur in the range $\sim 3.3-5 \%$.

\section{I S C U S S I O N}

Both the previous theoretical study (Latham et al. 2000) and this experimental one were aimed at elucidating the link between the fraction of endogenously active cells and network firing patterns. To this end, two sets of experiments were performed. In the first, we tested whether cultured neuronal networks firing at low rates contained endogenously active cells. Cells were identified as endogenously active if they fired when synaptic transmission was blocked by neurotransmitter receptor antagonists, tetanus toxin, or both. We found that every culture that fired at low rates contained endogenously active cells, and that the mean fraction was relatively high, $\sim 30 \%$ on average. We then tested whether a reduction in the fraction of endogenously active cells would lead to bursting. We were able to reduce the fraction of endogenously active cells by changing from a fortified media to a reduced one, the latter containing only the essential salts and no other factors. We found that cultures in reduced media, which contained few endogenously active cells, showed striking bursting behavior. Bursting was never observed in cultures in fortified media. These results, and the theoretical analysis presented in the previous paper, show that there is a transition first from steady firing to bursting and then from bursting to silence as the fraction of endogenously active cells decreases.

\section{Are the cells really endogenously active?}

It is critical to the interpretation of our experiments that activity in the presence of the neurotransmitter blockers we used implies endogenous activity. There are, however, at least three other possible explanations for the observed activity: 1) the act of patching a cell may have caused it to fire, 2) the neurons may have degraded during the course of the experiments, and 3) the block may have been incomplete.

To guard against the first possibility, we minimized perturbation to the cells by using extracellular patch recordings. These recordings leave the cell membrane intact and thus do not modify the intracellular media. Although there is still the possibility of damage to the cell that could cause a leakage current and thus lead to activity, the length and stability of our recordings make this unlikely: all extracellular patch recordings were at least $5 \mathrm{~min}$, and in a few cases we extended the recordings to $\sim 30 \mathrm{~min}$ without observing any drift in firing rate.

To verify that the neurons remained healthy throughout the course of the experiments, in several cases we returned antagonist-treated cells to control media and reexamined their firing patterns. In all cases the neurons reverted to the steady firing patterns exhibited before the cultures were placed in antagonists, and they showed the same range of mean firing rates.

Finally, we took two steps to ensure that transmission was completely blocked. First, we performed whole cell recordings to test for fast postsynaptic potentials, and found none. Second, we blocked transmission both postsynaptically, with neurotransmitter receptor antagonists, and presynaptically, with tetanus toxin, and found virtually identical results.

Thus we conclude that cells that were active in the presence of the blockers we used were endogenously active.

\section{Relationship between media and firing patterns}

The experiments using fortified and reduced media gave us a tight estimate of the fraction of endogenously active cells required to maintain steady firing. Although the fraction of endogenously active cells in fortified media was $30 \%$ on average, fractions as low as $5 \%$ were seen. This was close to the largest fraction in reduced media, which was $3.3 \%$. If the only effect of the reduced media was to decrease the fraction of endogenously active cells, then the transition to bursting occurred at a fraction between $\sim 3.3$ and $\sim 5 \%$. However, other confounding factors are possible. The reduced media could have effects on network and single cell properties besides altering the fraction of endogenously active cells. The degree of spike-frequency adaptation and the overall network firing rate, for example, could also affect whether or not a network bursts. Thus, although our experiments show a strong correlation between the fraction of endogenously active cells and bursting, other effects of the media could play a role. Consequently, the actual transition could have occurred outside the range $\sim 3.3-5 \%$. Nonetheless, these results form a solid first estimate of the critical transition range.

Although changing from fortified to reduced media was extremely effective in reducing the fraction of endogenously active cells, we were unable to establish the reason for its effectiveness. We did, however, rule out several possibilities. First, the effect was not due to differences in the concentration of the divalent cations $\mathrm{Ca}^{2+}$ and $\mathrm{Mg}^{2+}$, because the concentrations were the same in both media $(1.8$ and $0.8 \mathrm{mM}$, respectively). Reduced media did have a slightly lower concentration of $\mathrm{K}^{+}$than fortified media, 4.5 versus $5.6 \mathrm{mM}$. This may have lowered the neurons' resting membrane potential in reduced media, which could, in principle, reduce the fraction of endogenously active cells. However, increasing the $\mathrm{K}^{+}$concentration to $5.6 \mathrm{mM}$ in reduced media had no effect on bursting. Finally, the results were not due to differences in horse serum or conditioning (co-culturing for extended periods with glial cells): cells examined in growth media, which contained horse serum and were conditioned, and cells examined in $\mathrm{NaPO}_{4}$ buffered media, which did not contain horse serum and were not conditioned, produced essentially identical firing patterns and levels of endogenous activity.

An alternative method for reducing the fraction of endogenously active cells would have been to alter the $\mathrm{K}^{+}$concentration, which plays the dominant role in determining a cell's resting membrane potential. However, this may have unwanted side effects: spike-frequency adaptation, which is essential for bursting (Latham et al. 2000), often relies on a $\mathrm{Ca}^{2+}$-activated $\mathrm{K}^{+}$current, so modifying the concentration of the latter could affect the degree of spike-frequency adaptation and thus whether or not a network bursts. For this reason, and because we found that a media change could reduce the fraction of endogenously active cells without modifying the $\mathrm{K}^{+}$concentration, we did not explore this possibility. 
Finally, to eliminate the possibility that the reduced media was in some way damaging the cells, cultures were cycled from fortified to reduced to fortified media. After the second switch from reduced to fortified media, cells returned to their characteristic irregular firing patterns and low rates. In addition, when antagonists were added after the second switch, the fraction of endogenously active cells returned to their characteristic levels of $\sim 30 \%$.

\section{Was the bursting a network phenomenon?}

It is possible that the bursting observed in the reduced media was not a network phenomenon. This might occur if the reduced media changed all cells into endogenous bursters whose firing patterns were independent of, or only weakly dependent on, other cells in the network. Two lines of evidence argue against this. First, in reduced media the cells were not endogenous bursters: in the presence of antagonists they were either silent or firing steadily. Second, within each of the cultures containing reduced media, the variation in the period was relatively small, ranging from 2 to $20 \%$. This was comparable to the drift in burst period seen for individual cells, which ranged from 4 to $18 \%$ as determined by comparing the first half of the recording to the last half. Taken together, these two lines of evidence provide strong indication that the observed bursting in recording media is a network phenomenon.

\section{Role of endogenously active cells in shaping network firing patterns}

In the previous paper, we developed a theoretical model that described the intrinsic dynamics in large networks of excitatory and inhibitory neurons. This model indicated that a key parameter in controlling firing patterns was the fraction of endogenously active cells: when the fraction is above some threshold, steady firing at low rates is possible; when the fraction falls below that threshold, there is a transition to bursting; and when there are no endogenously active cells in a network, the network either falls silent or fires at high rate.

A somewhat surprising outcome of our model is the existence of a transition to bursting as the fraction of endogenously active cells decreases. The origin of this transition, however, can be explained simply: network bursting is caused by periodic crashes to zero firing rate followed by recovery. In our model, the crash to zero is induced by spike-frequency adaptation: repetitive firing introduces a hyperpolarizing current sufficient to temporarily eliminate endogenously active cells; without those cells, the low firing rate equilibrium vanishes and the network becomes silent. When there are fewer endogenously active cells in the network to begin with, it is easier to eliminate them. It is this last observation that explains the transition to bursting as the fraction of endogenously active cell decreases.

Previous experimental studies have examined the transition to bursting using pharmacological agents that, presumably, did not change the fraction of endogenously active cells. Bursting in these experiments was typically induced in one of two ways: 1) with neurotransmitter antagonists that block inhibition (Gross 1994; Gross et al. 1995; MacDonald and Barker 1981; Streit 1993) and 2) with neuromodulators that enhance the level of spike-frequency adaptation (Berkinblit et al. 1978;
Kudo and Yamada 1987; Zoungrana et al. 1997). Although these two experimental approaches appear unrelated, our theory provides a link between them: in both, bursting is produced by the elimination of endogenously active cells. In the first case, disinhibition causes firing rates to go up, which enhances the hyperpolarizing current associated with spike-frequency adaptation. This temporarily eliminates endogenously active cells and produces the requisite crash to zero firing rate that leads to bursting. In the second case, neuromodulators that increase the level of spike-frequency adaptation cause more endogenously active cells to be eliminated during repetitive firing, again facilitating bursting.

In the experiments reported here, we directly, rather than indirectly, explored the effect of endogenously active cells on firing patterns. We showed, first, that all cultures examined that fired at low rates contained endogenously active cells. Although this does not prove that endogenously active cells are necessary for low firing, it is a critical test of our theory. We then showed that a reduction in the fraction resulted in bursting. This result is not only consistent with theory, it also lends support to the notion that endogenously active cells are necessary for low firing rates, because it implies that a further reduction to zero endogenously active cells would result in a silent network: once a network crashes to zero firing rate, without endogenously active cells it has no way to recover and resume firing.

These experiments emphasize the critical role of endogenously active cells in shaping network behavior. Moreover, the observed agreement between theory and experiment provides evidence that we have developed a realistic model for the intrinsic dynamics of large neuronal networks. This model provides a framework for understanding the dynamic interactions that lead to stable firing patterns (steady firing at low rates and rhythmic bursting) and for understanding the transitions between those firing patterns. It thus lays the groundwork for detailed models of network function that will ultimately be needed for understanding how networks compute.

We thank C. Del Negro and M. Wiener for insightful discussions and comments on this manuscript.

Address for reprint requests: P. E. Latham, Dept. of Neurobiology, UCLA, Box 95-1763, Los Angeles, CA 90095-1763.

Received 5 March 1999; accepted in final form 30 September 1999.

\section{REFERENCES}

Basarsky, T. A., Parpura, V., and Haydon, P. G. Hippocampal synaptogenesis in cell culture: developmental time course of synapse formation, calcium influx, and synaptic protein distribution. J. Neurosci. 14: 64026411, 1994.

Bergey, G. K., Bigalke, H., and Nelson, P. G. Differential effects of tetanus toxin on inhibitory and excitatory synaptic transmission in mammalian spinal cord neurons in culture: a presynaptic locus of action for tetanus toxin. J. Neurophysiol. 57: 121-131, 1987.

Bergey, G. K., Macdonald, R. L., Habig, W. H., Hardegree, M. C., and Nelson, P. G. Tetanus toxin: convulsant action on mouse spinal cord neurons in culture. J. Neurosci. 3: 2310-2323, 1983.

Berkinblit, M. B., Deliagina, T. G., Feldman, A. G., Gelfand, I. M., And OrLOVSKY, G. N. Generation of scratching. I. Activity of spinal interneurons during scratching. J. Neurophysiol. 41: 1040-1057, 1978.

BETZ, H. Glycine receptors: heterogeneous and widespread in the mammalian brain. Trends Pharmacol. Sci. 14: 458-461, 1991.

Collingridge, G. L. AND LeSTER, R.A.J. Excitatory amino acid receptors in the vertebrate central nervous system. Pharmacol. Rev. 41: 143-210, 1989. 
Colquhoun, L. M. And Patrick, J. W. Pharmacology of neuronal nicotinic acetylcholine receptor subtypes. Adv. Pharmacol. 39: 191-220, 1997.

DeKhuiJzen, A. J. AND BAGUST, J. Analysis of neural bursting: nonrhythmic and rhythmic activity in isolated spinal cord. J. Neurosci. Methods 67: 141-147, 1996

FitzGERALD, S. C. Dissociated spinal cord-dorsal root ganglion cultures on plastic tissue culture dishes and glass coversips and wells. In: A Dissection and Tissue Culture Manual for the Nervous System, edited by A. Shahar, J. de Vellis, A. Vernadakis, and B. Haber. New York: Liss, 1989, p. 219-222.

GRoss, G. W. Internal dynamics of randomized mammalian neuronal networks in culture. In: Enabling Technologies for Cultured Neural Networks, edited by D. A. Stenger and T. M. McKenna. San Diego, CA: Academic, 1994, p. 277-317.

Gross, G. W., Rhoades, B. K., Azzazy, H.M.E., And Wu, M.-C. The use of neuronal networks on multielectrode arrays as biosensors. Biosensors Bioelectron. 10: 553-567, 1995.

Gross, G. W., Rhoades, B. K., and Kowalski, J. M. Dynamics of burst patterns generated by monolayer networks in culture. In: Neurobionics, edited by H. W. Bothe, M. Samii, and R. Eckmiller. Amsterdam: Elsevier, 1993, p. $89-121$

Hamill, O. P., Marty, A., Neher, E., Sakmann, B., and Sigworth, F. J. Improved patch-clamp techniques for high resolution current recordings from cells and cell-free membrane patches. Pflügers Arch. 391: 85-100, 1981.

Kamioka, H., Maeda, E., Jimbo, Y., Robinson, H.P.C., and Kawana, A. Spontaneous periodic synchronized bursting during formation of mature patterns of connections in cortical cultures. Neurosci. Lett. 206: 109-112, 1996.

KERNELL, D. The adaptation and relation between discharge frequency and current strength of cat lumbosacral motoneurons stimulated by long-lasting injected currents. Acta Physiol. Scand. 65: 65-73, 1965.

KERNELL, D. The early phase of adaptation in repetitive discharges of cat spinal motoneurons. Brain Res. 41: 184-186, 1972.

Kudo, N. AND YAmADA, T. $N$-methyl-D,L-aspartate-induced locomotor activity in a spinal cord-hindlimb muscles preparation of the newborn rat studied in vitro. Neurosci. Lett. 75: 43-48, 1987.

Latham, P. E., Richmond, B. J., Nelson, P. G., and NirenberG, S. N. Intrinsic dynamics in neuronal networks. I. Theory. J. Neurophysiol. 83: $808-827,2000$.
MacDonald, R. L. AND BARKER, J. L. Neuropharmacology of spinal cord neurons in primary dissociated cell culture. In: Excitable Cells in Tissue Culture, edited by P. G. Nelson and M. Lieberman. New York: Plenum, 1981, p. 81-110.

Malcangio, M. And Bowery, N. G. GABA and its receptors in the spinal cord. Trends Pharmacol. Sci. 17: 457-462, 1996.

Mayer, M. L. AND Westbrook, G. L. The physiology of excitatory amino acids in the vertebrate central nervous system. Prog. Neurobiol. 28: 197276, 1987.

Nelson, P. G., Fields, R. D., Yu, C., And Neale, E. A. Mechanisms involved in activity-dependent synapse formation in mammalian central nervous system cell cultures. J. Neurobiol. 21: 138-156, 1990.

Nelson, P. G., Neale, E. A., And Macdonald, R. L. Electrophysiological and structural studies of neurons in dissociated cell cultures of the central nervous system. In: Excitable Cells in Tissue Culture, edited by P. G. Nelson and M. Lieberman. New York: Plenum, 1981, p. 39-80.

Nelson, P. G., Yu, C., Fields, R. D., And Neale, E. A. Synaptic connections in vitro: modulation of number and efficacy by electrical activity. Science 244: 585-587, 1989

Romijn, H. J., Habets, A.M.M.C., Mud, M. T., And Wolters, P. S. Nerve outgrowth, synaptogenesis and bioelectric activity in fetal rat cerebral cortex tissue cultured in serum-free chemically defined medium. Dev. Brain Res. 2: 583-589, 1982

Sheng, H. Z., FIElds, R. D., AND Nelson, P. G. Specific regulation of immediate early genes by patterned neuronal activity. J. Neurosci. Res. 35: 459-467, 1993.

STREIT, J. Regular oscillations of synaptic activity in spinal networks in vitro. J. Neurophysiol. 70: 871-878, 1993.

TsEng, G.-F. AND PRINCE, D. A. Heterogeneity of rat corticospinal neurons. J. Comp. Neurol. 335: 92-108, 1993.

Wang, F. Z., Nelson, P. G., Fitzgerald, S. C., Hersh, L. B., and Neale, E. A. Cholinergic function in cultures of mouse spinal cord neurons. J. Neurosci. Res. 25: 312-323, 1990.

Zoungrana, O. R., Amri, M., CAR, A., And Roman, C. Intracellular activity of motoneurons of the rostral nucleus ambiguus during swallowing in sheep. J. Neurophysiol. 77: 909-922, 1997. 